\title{
A new family of mouse homeo box- containing genes: molecular structure, chromosomal location, and developmental expression of $\mathrm{Hox}-7.1$
}

\author{
Robert E. Hill, Pamela F. Jones, ${ }^{1,3}$ Anthony R. Rees, ${ }^{1}$ Christina M. Sime, Monica J. Justice, ${ }^{2}$ \\ Neal G. Copeland, ${ }^{2}$ Nancy A. Jenkins, ${ }^{2}$ Elizabeth Graham, and Duncan R. Davidson \\ Developmental Genetics Group, MRC Human Genetics Unit, Western General Hospital, Edinburgh EH4 2XU, UK; \\ ${ }^{1}$ Laboratory of Molecular Biophysics, Department of Zoology, University of Oxford, Oxford OX1 3QU, UK; ${ }^{2}$ Mammalian \\ Genetics Laboratory, BRI-Basic Research Program, NCI-Frederick Cancer Research Facility, Frederick, Maryland 21701 \\ USA
}

Two families of homeo box-containing genes have been identified in mammals to date, the Antennapedia- and engrailed-like homeo boxes, based on the sequence similarity to those from Drosophila. Here, we report the isolation of a homeo box-containing gene that belongs to a new family of which there are at least three related genes in the mouse genome. The homeo box of this new gene shows remarkable similarity to the Drosophila Msh homeo box that we designate as the prototype for this family. The gene maps to the proximal end of mouse chromosome 5 and does not cosegregate with any known homeo box-containing gene. We designate this locus Hox-7.1. In situ hybridizations to mouse embryos at different stages show a unique pattern of expression, as compared to other homeo box-containing genes described thus far. Hox-7.1 transcripts are detected in 9.5-dayold embryos in the neural crest, developing limb bud, and visceral arches. Later, this gene is expressed in regions of the face that are derived from neural crest and in the interdigital mesenchymal tissues in both the fore- and hindlimbs.

[Key Words: Mouse homeo box; Hox-7.1; cDNA; sequence; expression; chromosomal location]

Received October 10, 1988; revised version accepted November 15, 1988.

A highly conserved sequence common to developmental genes in Drosophila has provided a means to identify genes that may be involved in controlling mammalian development. This conserved 180-bp stretch of DNA, the homeo box, was originally identified in Drosophila developmental genes involved in homeotic mutations (McGinnis et al. 1984a,b; Scott and Weiner 1984) and subsequently found in other developmental control genes such as segmentation genes (Scott and Weiner 1984; Poole et al. 1985; Macdonald et al. 1986) and maternal genes (Mlodzik et al. 1985; Frigerio et al. 1986). The interspecific conservation of this DNA domain is evidenced by its presence in a wide range of metazoans including vertebrates. Drosophila homeo box sequences have been used to isolate homeo box-containing genes from vertebrates, including Xenopus (Carrasco et al. 1984; Muller et al. 1984; Harvey et al. 1986), human (Levine et al. 1984; Boncinelli et al. 1985; Simeone et al. 1986; Mavilio et al. 1986), and mouse (see Holland and Hogan 1988).

Several lines of evidence suggest that the Drosophila

${ }^{1}$ Program and data base are a result of a collaboration between Leeds and Birkbeck College, London Universities, under the direction of the SERC Biotechnology Directorate.

${ }^{3}$ Present address: Department of Cell Biology, Biozentrum, University of Basel, Klingelbergstrasse 70, CH-4056 Basel, Switzerland. homeo box genes encode regulatory proteins which, by sequence specific recognition, bind DNA. The homeo box domain of the protein product has structural similarity to the helix-turn-helix DNA-binding domain of some regulatory proteins in yeast and prokaryotes (Shepherd et al. 1984; Laughon et al. 1985). Homeo box-containing proteins have been localized intracellularly to the nucleus (White and Wilcox 1984; Beachey et al. 1985; Carroll and Scott 1985; DiNardo et al. 1985) and have been shown to exhibit DNA-binding activity in vitro (Desplan et al. 1985). Furthermore, genetic experiments in Drosophila suggest that some of these proteins exhibit a regulatory role by controlling the expression of other developmental genes (see Akam 1987; Ingham 1988).

The homeo boxes in Drosophila can be divided into three families based on sequence characteristics of which Antennapedia (Antp), engrailed (en), and paired are the prototypes (Gehring 1987a). Homeo box sequences can be similarly classified in mammals. The majority of mammalian genes containing homeo boxes are most closely related to the Antp family. These genes, of which $>18$ have been identified, are situated in three major clusters in the mouse genome localized on chromosome 6 (Hox-1) (Colberg-Poley et al. 1985; Bucan et 
al. 1986; Baron et al. 1987), 11 (Hox-2) (Hart et al. 1985; Joyner et al. 1985; Rabin et al. 1985; Munke et al. 1986; Meijlink et al. 1987), and 15 (Hox-3) (Awgulewitsch et al. 1986; Rabin et al. 1986; Breier et al. 1988), with several others scattered throughout the genome (Hox-4, Hox-5, and Hox-6) (Lonai et al. 1987; Featherstone et al. 1988; Sharpe et al. 1988). Two unlinked genes that map to chromosomes 1 and 5 in the mouse contain homeo boxes homologous to the Drosophila en family (Hill et al. 1987; Joyner and Martin 1987). These genes display additional sequence similarity to the Drosophila genes in adjacent regions outside the homeo box. There has been no report of any paired-type homeo box in mouse.

Another Drosophila homeo box that has diverged quite significantly from members of these three families has recently been isolated. This single gene has been termed Msh (for muscle segment homeo box) or 99B (its chromosomal mapping position) (Gehring 1987b; B. Jacq, pers. comm.). Here, we report the identification of a mouse gene that contains a homeo box most similar to that of $M s h$. There are at least three related genes in the mouse genome; therefore, these represent a fourth family of homeo boxes, which we have designated the Msh family. The mouse gene, which is termed Hox -7.1 , maps to the proximal region of chromosome 5, 2-3 cM distal to the mouse En-2 gene (en-like homeo box), but more closely linked (within $1 \mathrm{cM}$ ) to the mouse homolog of D4S43, a human probe closely linked to Huntington's disease. This establishes the mouse gene as a new homeo box locus. In situ analysis of expression shows that this gene has a unique pattern of expression among the homeo box genes studied thus far.

\section{Results}

\section{Isolation of a homeo box-containing cDNA}

We screened a $\lambda g t 10$ cDNA library prepared from mouse 8.5-day embryos (Fahrner et al. 1987) to isolate genes containing the homeo box domain. Hybridization conditions of reduced stringency were used in an attempt to select genes that have diverged significantly from the Drosophila Antp family of homeo boxes. Previously, using the Drosophila ftz gene (a member of the Antp familyl, we isolated a divergent cDNA that we showed was derived from the mouse Hox-1.6 gene (Baron et al. 1987). This gene contains a homeo box that shows $\sim 65 \%$ similarity to the Antp and $f t z$ homeo boxes. In this study, we comparatively screened the above library with the Hox-1.6 cDNA and the $f t z$ gene and selected clones that hybridized with low intensity to $H O x-1.6$ and undetectably to the Drosophila $\mathrm{ftz}$ gene. A $\lambda$ gt 10 clone was isolated containing a $1.5-\mathrm{kb}$ insert that was subcloned into a plasmid vector and is referred to as pMH 2.

Northern analysis of RNAs from a series of embryonic stages showed that the transcript, detected by the pMH $\lambda 2$ probe, was expressed in embryonic RNA isolated from the earliest stage of 9-day post coitum, with an apparent decrease at later stages (Fig. 1). A single mRNA species was detected that migrates at the posi-

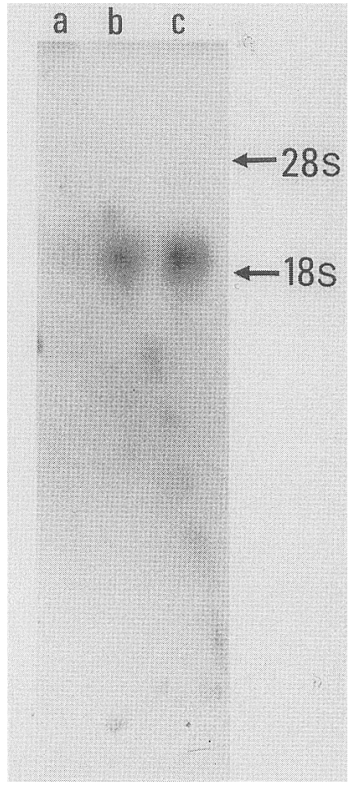

Figure 1. Northern blot analysis of Hox-7.1 mRNA from mouse embryos at various stages. Total mRNA isolated from 14.5- (lane $a$ ), 11.5- (lane $b$ ), and 9-day (lane $c$ ) mouse embryos.

tion of the 18S rRNA, suggesting that the size of the mRNA is $-2-2.2 \mathrm{~kb}$. To obtain a full-length cDNA, subcloned fragments from the $5^{\prime}$ end of the cDNA were used to rescreen the $\lambda \mathrm{gt} 10$ cDNA library, and a $1.8 \mathrm{-kb}$ cDNA was isolated. Taking into account a 100- to 150nucleotide contribution by the poly(A) region to the mRNA length, this cDNA may approximate the size of the full-length mRNA.

\section{Primary structure of the homeo box-containing gene}

The nucleotide sequence of the $1.8-\mathrm{kb}$ cDNA is presented in Figure 2. A long open reading frame is encoded by this cDNA, which is in frame with the predicted homeo box domain. There are three methionine codons in this frame toward the 5'end of the cDNA, which we have considered as possible translation initiation sites. The first ATG (five codons upstream of the predicted open reading frame in Fig. 2) is in an unfavorable sequence context for a translational start site (Kozak 1987). The other two (underlined in Fig. 2) are in a more favorable context for the Kozak consensus sequence. In most cases, the first ATG that conforms to Kozak's rules is the predominant initiation site (Kozak 1987); therefore we have deduced the protein sequence from this site. One other ATG, found in the $5^{\prime}$-untranslated region of the cDNA (starting at nucleotide 74), that is not in frame with the homeo box would code for a short polypeptide of 24 amino acids. The significance of this short open reading frame is unknown; however, the presence of upstream ATG codons has been reported in other homeo box genes (Breier et al. 1988), and approximately two thirds of the known proto-oncogenes contain short 5 ' open reading frames (Kozak 1987). 


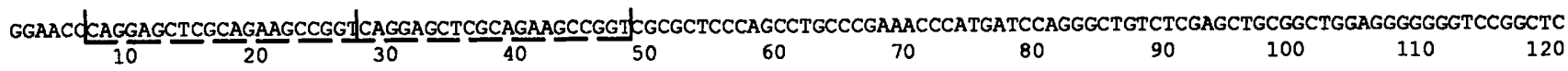

MetThrSerLeuProLeuGlyValLysVa IGluAspSerAlaPheAlaLysProAlaGlyGlyGlyValGIyGInAlaProGlyAlaAlaAlaAlaThr TGCATGGCCCCGGCTGCTGCTATGACTTCTTTGCCACTCGGTGTCAAAGTGGAGGACTCCGCCTTCGCCAAGCCTGCTGGGGGAGGCGTTGGCCAAGCCCCCGGGCTGCTGCGGCCACC

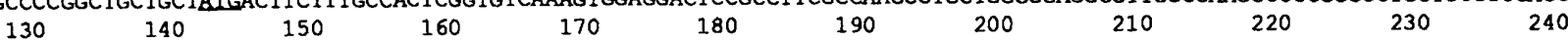

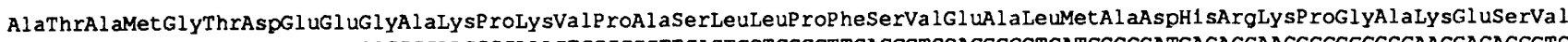
GCAACCGCCATGGGCACAGATGAGGAGGGGGCCAAGCCCAAAGTGCCCGCTTCACTCCTGCCCTTCAGCGTGGAGGCCCTCATGGCCGATCACAGGAAGCCCGGGCCAAGGAGAGCGTC $\begin{array}{lllllllllll}250 & 260 & 270 & 280 & 290 & 300 & 310 & 320 & 330 & 340 & 350\end{array}$

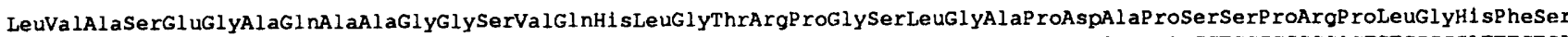
CTGGTGGCCTCCGAAGGGGCTCAGGCAGCGGGTGGCTCGGTGCAGCACTTGGGCACCCGGCCCGGGTCTCTGGGCGCCCCGGATGCGCCCTCCTCGCCGCGGCCTCTCGGCCATTTCTCA

390 400 410 420 430 440 450 460 470

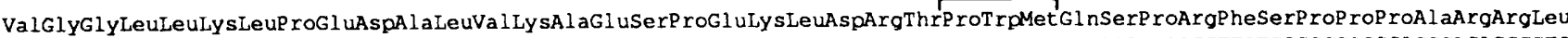
GTCGGAGGACTCCTCAAGCTGCCAGAAGATGCTCTGGTGAAGGCCGAAAGCCCCGAGAAACTAGATCGGACCCCGTGGATGCAGAGTCCCCGCTTCTCCCCGCCCCCAGCCAGACGGCTG 510 52 530 540 550 560 570 58 590 600 SerProProAlaCysThrLeuArgLysH1 sLysThn AsnArgLysP roArgThrProPheThrThrAlaGI nLeuLeLAlaLeuGl UArgLysPheArgGlnLysG1 nTyrLeuSerI le AGTCCCCCAGCATGCACCCTACGCAAGCACAAGAC AACCGCAAGCCCAGGACGCCTTTCACCACAGCTCAGCTGCTGGCTCTGGAGCGCAAGTTCCGCCAGAAGCAGTACCTGTCTATT

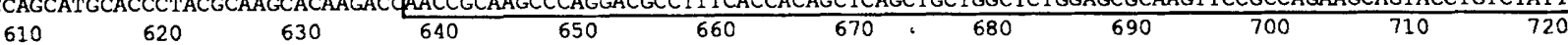

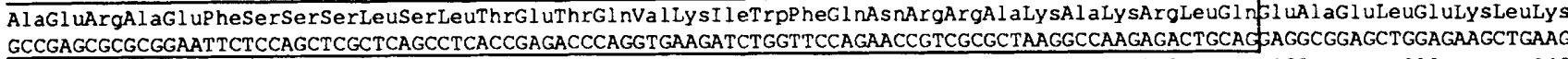
$\begin{array}{lllllllll}730 & 740 & 750 & 760 & 770 & 780 & 790 & 800 & 810\end{array}$

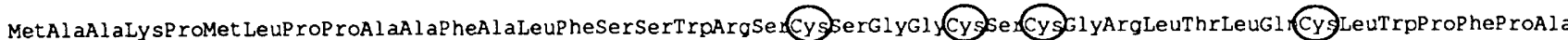
ATGGCCGCGAAACCCATGTTGCCGCCTGCTGCCTTCGCTCTCTTTTCCTCTTGGCGGTCCTGCAGCGGTGGCTGCAGCTGCGGGCGCCTCACTCTACAGTGCCTCTGGCCCTTTCCAGCG $\begin{array}{lllllllll}850 & 860 & 870 & 880 & 890 & 900 & 910 & 920 & 930\end{array} 9$

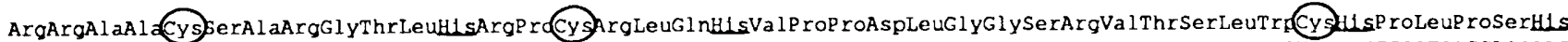
CGCCGCGCTGCCTGTAGCGCCCGTGGGACTCTACACCGCCCATGTAGGCTACAGCATGTACCACCTGACTTAGGTGGGTCCAGAGTCACCTCCCTGTGGTGCCATCCCCTCCCCAGCCAC $\begin{array}{llllllllll}970 & 980 & 990 & 1000 & 1010 & 1020 & 1030 & 1040 & 1050 & 1060\end{array}$

LeuPheGIuGlnSerSerGlySerProSer * *

CTCTTTGAGCAGAGCAGCGGGAGTCCTTCCTAGGAAGCTCTGCTGCCCTATACCACCTGGTCCCTTCTCTTAAACCCCTTGCTACACACTTCCTCCTGGTTGTCGCTTCCTAAACCTTCC $1090 \quad 1100 \quad 1110 \quad 1120 \quad 1130 \quad 1140 \quad 1150 \quad 1190 \quad 1170$

TCATCTGACCCCTTCTGGGAAGAAAAAGAATTGGTCGGAAGATGTTCAGGTTTTTCGAGTTTTTTCTAGATTTACATGCGCAAGTTATAAAATGTGGAAACTAAGGATGCAGAGGCCAAG $\begin{array}{llllllllll}1210 & 1220 & 1230 & 1240 & 1250 & 1260 & 1270 & 1280 & 1290 & 1300\end{array}$

AGATTTATCCGTGGTCCCCAGCAGAATTAGAGGCTGAAGGAGACCAGAGGCCAAAAGGACTAGAGGCCATGAGACTCCATCAGCTGCTTCCGGTCCTGAAACCAGGCAGGACTTGCACAG $\begin{array}{lllllllllll}1330 & 1340 & 1350 & 1360 & 1370 & 1380 & 1390 & 1400 & 1410 & 1420 & 1430\end{array}$

AGAAATTGCTAAGCTAATCGGTGCTCCAAGAGATGAGCCCAGCCCTATAGAAAGCAAGAGCCCAGCTCCTTCCACTGTCAAACTCTAAGCGCTTTGGCAGCAAAGCATTGCTCTGAGGGG $\begin{array}{lllllllll}1450 & 1460 & 1470 & 1480 & 1490 & 1500 & 1510 & 1520 & 1530\end{array}$

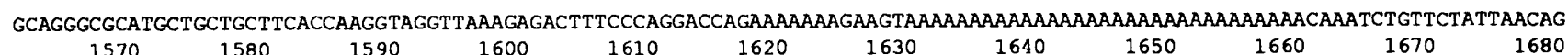

TACATTTTCGTGGCTCTCAAGCATCCCTTTTGAAGGGACTGGTGTGTACTATGTAATATACTGTATATTTGAAATTTTATTATCATTTATATTATAGCTATATTTGTTAAATAAATTAAT

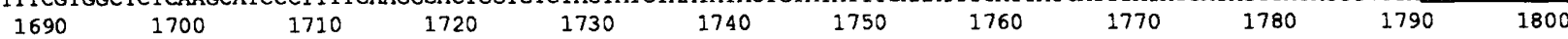

TTTAAGCTAC (A) $n$

1810

Figure 2. Nucleotide sequence of the $H o x-7.11 .8-\mathrm{kb}$ cDNA and deduced protein structure. The boxed 180 nucleotides starting at position 637 represent the homeo box domain. Upstream ATG codons that are underlined best fit the translation start site concensus sequence (Kozak 1987), and the underlined amino acids are the only three that conform to the conserved hexapeptide found in most homeo box-containing genes. The direct perfect 21 -bp repeat at the very $5^{\prime}$ end (starting at position 7 ) is indicated by dashed lines, and the putative overlapping poly(A) addition sites are underlined at the $3^{\prime}$ end of the cDNA. 
The predicted protein will contain 324 amino acids (m.w. 34,500). The coding region of the putative homeo box domain starts at nucleotide 637 of the cDNA (boxed region of Fig. 2). The stretch of protein to the carboxyterminal side of the homeo box is longer than that of other mammalian homeo box-containing genes reported to date. It is of particular interest that there is a high density of cysteine residues in this region of the protein (7 within a stretch of 54 amino acids), whereas only 1 other is found outside this region. This suggests that this region is constrained in a taut tertiary configuration involving disulfide bridges. Alternatively, these cysteine residues may be involved in intermolecular interactions with other proteins or in stabilizing binding to DNA. Histidines are also found in this region; however, this structure does not conform to the metal binding finger motif (Klug and Rhodes 1987; Evans and Hollenberg 1988).

Most homeo box-containing genes have a conserved hexapeptide sequence of Ile/Val-Tyr-Pro-Trp-Met-Arg, a short distance upstream of the homeo box (Mavilio et al. 1986; Kessel et al. 1987). However, this putative protein sequence contains only three of these amino acids (ProTrp-Met), starting 28 amino acids upstream of the homeo box (overlined in Fig. 2). Deviation from this consensus has also been reported for the Hox-1.6 gene, in which only two of the hexapeptide amino acids are present (Baron et al. 1987).

Two other features in the cDNA are noted. In the $5^{\prime}$ untranslated region starting at position 7 (indicated in Fig. 2 by a dashed line) are two copies of a direct perfect 21 -bp repeat. The function, if any, of these repeats may be of interest when determining the elements that regulate the expression of this gene. Using a matrix search program' (LUPES program made available by the SERC Protein Engineering Club), an 11-amino-acid sequence (starting with Pro at position 580) was found to have a high degree of resemblance $(>80 \%)$ to a consensus matrix for a cAMP-dependent protein kinase phosphorylation site (S. Cox and A.R. Rees, unpubl.). This is particularly interesting in light of the data suggesting that Drosophila en is phosphorylated (Gay et al. 1988).

The putative homeo box sequence shows $57 \%$ nucleotide similarity to mouse $\operatorname{Hox}_{-1.6}$ (the sequence used to isolate this genel, $<50 \%$ nucleotide similarity to either
Antp or $f t z$, and $55 \%$ similarity to the mouse and Drosophila en-like genes. Because this sequence differs considerably from other known homeo boxes and shows approximately the same low degree of similarity to both Antp-type and en-type homeo boxes this sequence cannot be considered to fit into either family. Recently, a new Drosophila homeo box sequence has been reported that is expressed in muscle segments and is located on Drosophila chromosome 3 near the tip of the right arm (at position 99B) (Gehring 1987b). This homeo box, termed $M s h$, shows $80 \%$ similarity to that of the mouse gene at the nucleotide level (data not shown) and $90 \%$ at the protein level (Fig. 3) (Msh protein sequence communicated by B. Jacq; also, B.D. Robert et al., in prep.). This homology extends outside the homeo box for 11 amino acids at the $3^{\prime}$ end. Unfortunately, very little sequence information is available for the region $5^{\prime}$ of the Drosophila homeo box. For the seven amino acids known, five are in common. Therefore, in view of the similarities between the mouse and Drosophila genes in and around the homeo box and the differences that exist with other known homeo box-containing genes, the Drosophila $\mathrm{Msh}$ and the mouse gene designate a new family of homeo box sequences. Because, as shown below, this gene is not closely linked to any of the known mouse homeo box-containing clusters (Hox-1, Hox-2, or Hox-3), this gene can be given a new Hox designation in agreement with previous mouse nomenclature (Martin et al. 1987). Therefore, we refer to this gene as $\operatorname{Hox}-7.1$.

\section{Multiple Msh-like genes in the mouse genome}

In a rescreen of the 8.5 -day embryonic $\lambda g t 10$ cDNA library, it became evident that there is at least one other related gene encoded by the mouse genome. Using the Hox-7.1 clone, pMH $\lambda 2$, as probe, a related but distinctly different cDNA was isolated. Preliminary analysis of this second $M s h$-like gene revealed a homeo box domain with $\sim 85 \%$ nucleotide similarity to that of the Hox -7.1 gene ( $R$. Hill, unpubl.). To determine whether there are any other related mouse genes, we have screened total mouse DNA by Southern blotting. Southern analysis of mouse DNA with this $H o x-7.1$-related cDNA detects a single restriction fragment that hybridizes to yield a

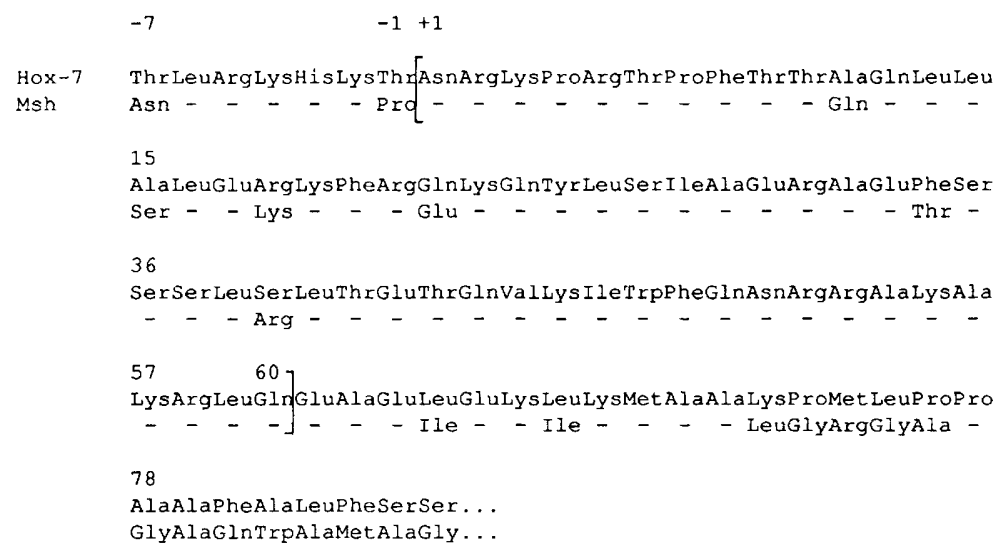

Figure 3. Comparison of the homeo box and surrounding regions of the Drosophila Msh and the mouse Hox-7.1 genes. The homeo box starts at position 1 and ends at 60 . Only the amino acids of Drosophila Msh that differ from those of Hox-7.1 are shown. 
dark signal and several less intensely hybridizing fragments, depending on the restriction endonucleases used (Fig. 4). From cosmid analysis of this gene, we know that the three restriction endonucleases used in this analysis do not cleave within the hybridizing region of the Hox-7.1-related gene. These minor fragments are therefore interpreted as representing other related genes in the genome. The Hox-7.1 homeo box-containing restriction fragments migrate with a molecular weight of $\sim 7.2$ $\mathrm{kb}$ (BamHI digestion), $5.5 \mathrm{~kb}$ (PstI digestion), and $0.25 \mathrm{~kb}$ (PvulI digestion). The BamHI (lanes 1-3) and PstI (lanes 7-9) digestions each generate a minor fragment with a molecular weight similar to the Hox-7.1 restriction fragment (indicated in Fig. 4) and at least one other. In this analysis, the $0.25-\mathrm{kb}$ PvuII fragment ran off the gel; however, this enzyme does generate one other detectable restriction fragment. These results imply that the mouse genome contains multiple related genes; the Hox-7.1 gene, the gene identified using the Hox-7.1-related cDNA, and at least one other (indicated in Fig. 4).

\section{Chromosomal location of Hox-7.1}

The chromosomal location of Hox-7.1 was determined using an interspecific mouse backcross mapping panel derived by crossing C57BL/6J and Mus spretus. This mapping panel has been typed for $>220$ distinct loci dis-

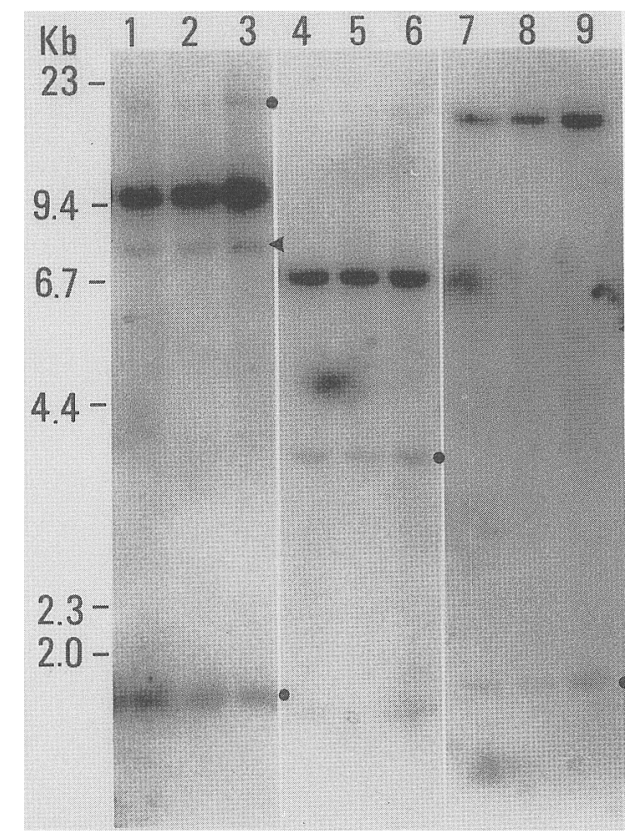

Figure 4. Southern analysis of the mouse genome using a Hox-7.1-related cDNA as probe. Mouse DNAs used were from C57BL/6 (lanes 1, 4, and 7), an outbred strain of mice (lanes 3, 6, and 91 , and the $F_{1}$ progeny from the two strains (lanes 2, 5, and 8). DNAs were digested with BamHI (lanes 1-3), PvuII (lanes 4-6), and Pst (lanes 7-9). The predicted positions of the Hox-7.1 homeo box-containing restriction fragments are indicated by arrowheads, and the putative additional related genes are indicated by dots. tributed over most mouse chromosomes. Digestion of C57BL/6J and $M$. spretus DNAs with PvuII and hybridization with the Hox-7.1 probe identified the restriction-fragment-length polymorphisms (RFLP) listed in Table 1. The RFLPs were used to follow the segregation of Hox-7.1 in 204 interspecific backcross mice. The mapping results indicated that Hox-7.1 is located on mouse chromosome 5 (Fig. 5). The relative gene order of Hox-7.1, with respect to six other chromosome 5 markers that have been typed in the interspecific backcross mice (Table 1), was determined by minimizing the number of double recombinants between loci (Fig. 5). Gus and $A l b$ were used as anchor loci. The distance between loci and their relative order proceeding distally from the most proximal marker is as follows: En-2-2.5 $\pm 1.1 \mathrm{cM}-I 1-6-2.5 \pm 1.1 \mathrm{cM}-D 4 S 43-$ $1.0 \pm 0.7 \quad \mathrm{cM}-\mathrm{Hox}-7.1-19.1 \pm 2.8 \quad \mathrm{cM}-\mathrm{Kit}-$ $5.9 \pm 1.6 \mathrm{cM}-A l b-20.6 \pm 2.8 \mathrm{cM}-$ Gus. The results of this analysis place Hox-7.1 between D4S43 and Kit on chromosome 5. Hox-7.1 does not map to any other homeo box-containing locus already mapped in mouse chromosomes, indicating that it is not part of a previously defined homeo box gene cluster.

\section{Distribution of Hox-7.1 expression in the mouse embryo}

We have examined, by in situ hybridization, the expression of Hox-7.1 in six mouse embryos between 9.5 and 13.5 days post coitum. Here, we describe the main features of the results. A more detailed analysis of the expression of this and other genes in this family will be published separately.

Sections of embryos at 9.5, 10.5, and 11.5 days of development were hybridized with probe 1 (the $3^{\prime}$ BglII fragment of $\mathrm{pMH} \lambda 2$; see Fig. 6). Labeling was observed in three main regions: the neural crests, a subset of tissues derived from the neural crests /visceral arches and craniofacial structures|, and the developing limb buds. In each of these tissues, expression was restricted to specific regions that did not have any histologically detectable morphological boundaries. The developing neural tube showed intense expression in the neural crests before and after fusion; less intense labeling extended over the dorsal half of the closed tube (Fig. 7A,B). In 9.5-day embryos, the frontal mesenchyme of the head was intensely labeled (data not shown): by 11.5 days, labeling in this region was confined to a thin layer of cells lying on the dorsal surface of the forebrain. Isolated cells in the dorsal and lateral regions of the developing integument (both in the mesechyme and epithelium) showed expression. Restricted parts of the visceral arches were labeled (Fig. 7C,D). The developing facial connective tissue showed intense expression in the prospective maxillary region. A restricted pattern of labeling was also observed in the fore- and hindlimb buds, with peak expression in the distal and posterior mesenchyme (Fig. $7 \mathrm{E}, \mathrm{F})$. At the resolution afforded by ${ }^{35} \mathrm{~S}$, it was not possible to determine whether expression was confined to the mesenchyme or whether parts of the epithelium 
Table 1. Chromosome 5 loci mapped in interspecific backcross mice

\begin{tabular}{|c|c|c|c|c|c|c|}
\hline Locus & Gene name & Probe & Enzyme & $\begin{array}{l}\text { C57BL/6J } \\
\text { fragment } \\
\text { sizes }(\mathrm{kb})\end{array}$ & $\begin{array}{l}\text { M. spretus } \\
\text { fragment } \\
\text { sizes }(\mathrm{kb})^{\mathbf{a}}\end{array}$ & Reference \\
\hline En-2 & Engrailed-2 & $\mathrm{mp} 2$ & PvuII & $5.3,1.5$ & $\underline{4.5}, \underline{2.4}$ & $\begin{array}{l}\text { Joyner and Martin (1987); } \\
\text { B.A. Mock et al. } \\
\text { (in prep.) }\end{array}$ \\
\hline $11-6$ & Interleukin-6 & Il-6 & BamHI & $10.2,5.2$ & $10.2, \underline{4.9}$ & $\begin{array}{l}\text { B.A. Mock et al. } \\
\text { (in prep.) }\end{array}$ \\
\hline$D 4 S 43$ & $\begin{array}{l}\text { a sequence tightly } \\
\text { linked to Huntington's } \\
\text { disease in humans }\end{array}$ & С9AHB 1.4 & PvuII & 19.0 & $\underline{13.2}$ & $\begin{array}{l}\text { Gilliam et al. (1987); } \\
\text { S.V. Cheng et al. } \\
\text { (in prep.) }\end{array}$ \\
\hline Hox -7.1 & Homeo box locus-7.1 & $\mathrm{pMH} \lambda 2$ & PvuII & $6.0,0.6$ & $\underline{6.5}, \underline{1.0}$ & \\
\hline Kit & Kit proto-oncogene & phckit-171 & BamHI & $17.8,2.0$ & $16.9,2.0$ & Yarden et al. (1987) \\
\hline$A l b$ & Albumin & AlbH & PstI & 5.1 & $\underline{9.4}$ & $\begin{array}{l}\text { B.A. Mock et al. } \\
\text { (in prep.) }\end{array}$ \\
\hline Gus & $\beta$-glucuronidase & pGus-1 & BamHI & $\begin{array}{c}16.5,9.1 \\
1.9\end{array}$ & $\frac{22.1}{\underline{3.7}}, 9.1$ & $\begin{array}{l}\text { Palmer et al. (1983); } \\
\text { B.A. Mock et al. } \\
\text { (in prep.) }\end{array}$ \\
\hline
\end{tabular}

anderlined restriction fragment sizes indicate the restriction fragments typed in the analysis.

were also labeled. Where the thickened apical ectodermal ridge was observed, it was labeled to a markedly lesser degree than the adjacent mesenchyme. In the present analysis, we have observed no expression in other organs except in red blood cells (RBC). The latter labeling may, however, be artifactual because these cells also labeled with the control probe and because nonspecific binding of other probes has been described (Davidson et al. 1988).

Probe 1, which represents the $3^{\prime}$ half of the pMH $\lambda 2$ cDNA, contains a short stretch of the homeo box sequence, $10 \%$ of the length of the probe (Fig. 6), and may therefore not be specific for the $H o x-7.1$ gene product. This raises the possibility that part of the pattern of labeling may reflect the expression of one of the other members of this gene family. To avoid this ambiguity, we investigated the expression of $\mathrm{Hox}_{-7.1}$ with a specific probe in a series of experiments on 13.5-day embryo. This probe (probe 2, see Fig. 6) comprises the 3' BssHII fragment and contains only material $3^{\prime}$ to the homeo box, $80 \%$ of which is in the $3^{\prime}$-untranslated region. The specificity of this probe is supported by Southern anal- ysis and by the different patterns of labeling obtained with this probe and one derived from the Hox-7.1-related cDNA described above (R. Hill, unpubl.).

The results of our experiments using probe 2 are consistent with the patterns found earlier in development using probe 1 and show additional points of interest. The major areas of labeling were in craniofacial structures (the developing maxillary, mandibular, and nasal structures processes) and in the interdigital soft tissue in the fore- and hindlimbs (Fig. 8). We have not detected expression in any other organs (except in RBCs), though we have not examined transverse sections that might reveal limited regions of expression, e.g., in the neural tube. A control probe comprising the sense strand complementary to probe 1 showed no specific patterns of labeling in sections adjacent to those described, except in regions abundant in RBCs.

\section{Discussion}

We have described the isolation of a homeo box-containing gene in mouse that is a member of a new homeo

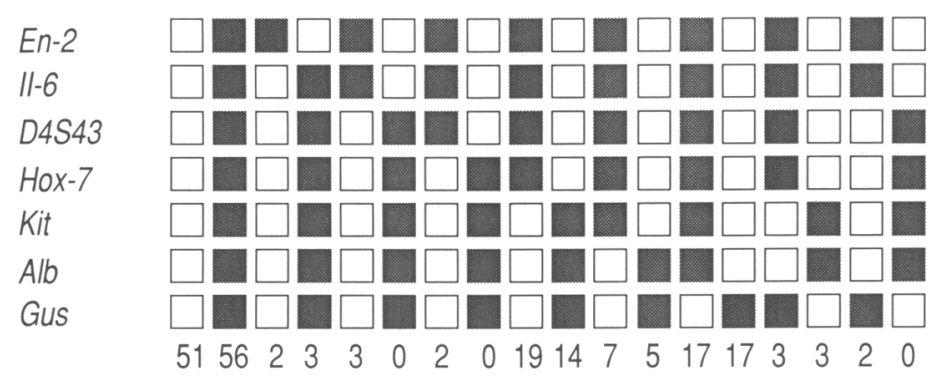

Figure 5. Summary of the results of the interspecific backcross analysis. (Left) Genes mapped in the analysis. Each column represents the chromosome identified in the $\mathrm{N}_{2}$ progeny that was inherited from the $(\mathrm{C} 57 \mathrm{BL} / 6 \mathrm{~J} \times M$. spretus) $F_{1}$ parent. The black boxes represent the presence of a C57BL/6J allele, and the white boxes represent the presence of a $M$. spretus allele. (Bottom) The number of each type of chromosome identified. The frequency of C57BL/6J and $M$. spretus alleles for all of the chromosome 5 loci examined in the $\mathrm{N}_{2}$ progeny did not differ significantly from the $50: 50$ ratio expected if each allele was transmitted in a normal Mendelian fashion from the $F_{1}$ parents to the $\mathrm{N}_{2}$ offspring. Eight double recombinants were observed, which is not significantly different from the expected number of double recombinants. 


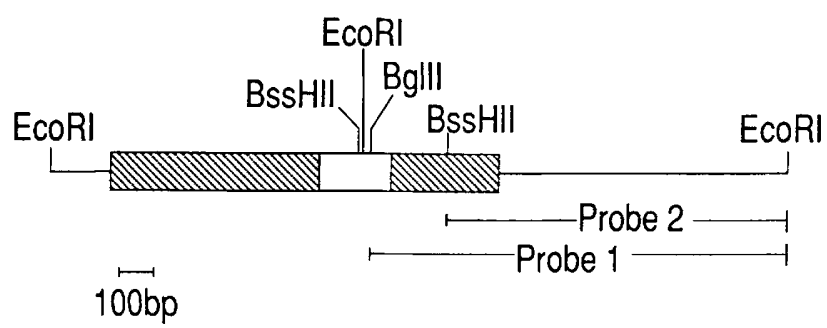

Figure 6. Diagram of the Hox-7.1 (pMH^2) cDNA and probes used for in situ hybridization. The hatched box represents the coding region, and the open box represents the homeo box. Regions of the cDNA used as probe for in situ are underlined.

box family. In this family, there are at least three related members in the mouse and one known in Drosophila called $M s h$. The comparison of the homeo box domain of the Drosophila gene and the newly isolated mouse gene called Hox-7.1 shows that these two genes share $90 \%$ amino acid similarity. The homology also extends outside the homeo box, which is reminiscent of the comparison of the mouse and Drosophila en-like genes (Joyner and Martin 1987).

The degree of sequence similarity that exists between the Hox-7.1 and Drosophila Msh genes indicates that the homeo box and surrounding regions existed before the branching of the evolutionary tree that resulted in the arthropod and vertebrate lineages. This interpretation poses the question, What has been responsible for the evolutionary conservation of this protein domain? In response to this question, we must consider that these evolutionary constraints reflect important functional properties of this protein domain. It has been argued that the predicted recognition helix of the helix-turn-helix domain (amino acids $42-50$ in Fig. 3) determines the specificity of DNA binding in this domain /see Gehring 1987a). The fact that this region is highly conserved among the known homeo boxes (with the exception of

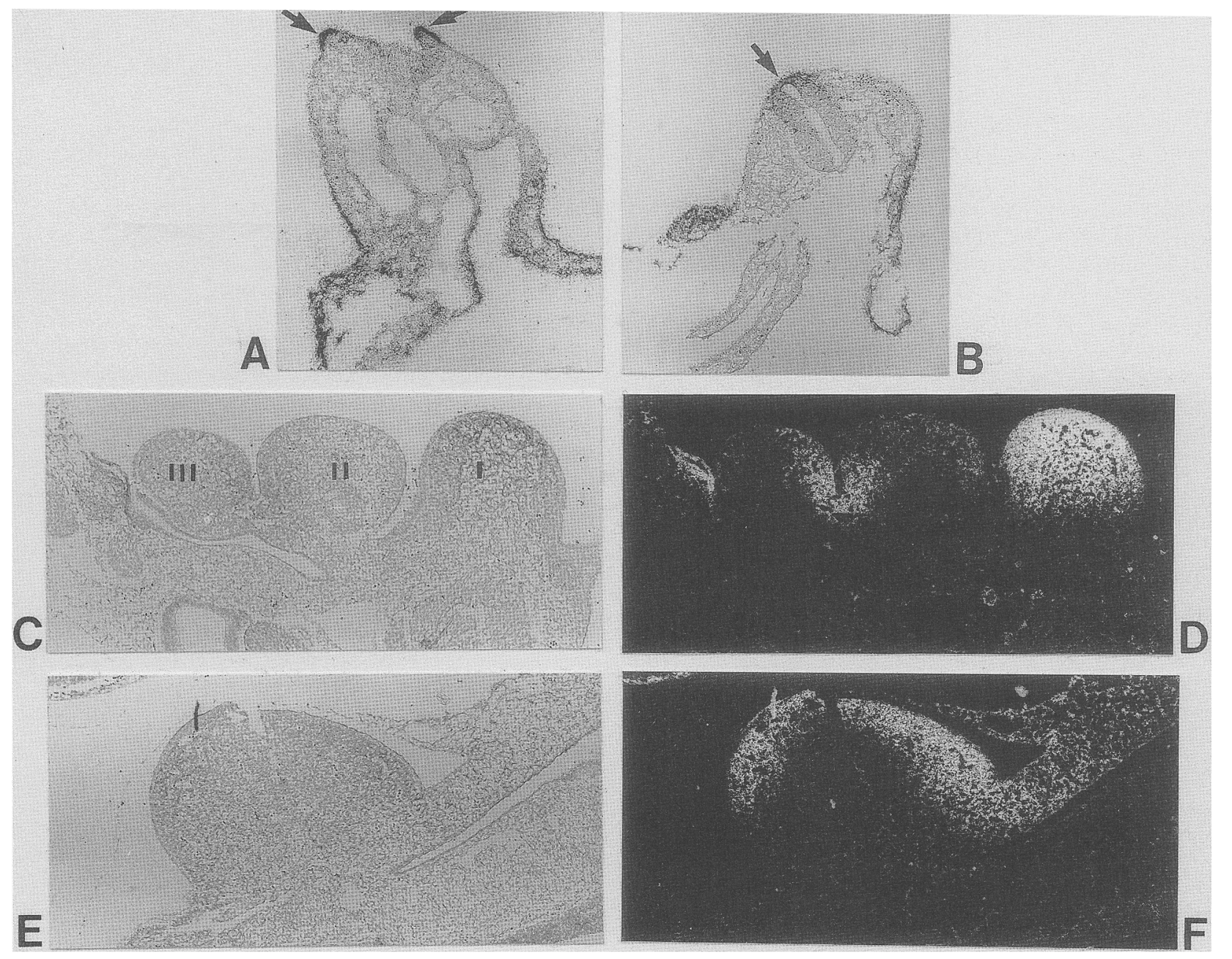

Figure 7. The pattern of expression of $\mathrm{Hox}^{-7_{M s h}}$ in 9.5-day mouse embryos. Transverse sections showing labeled neural crests, before $(A)$ and after $(B)$ closure of the neural tube (arrows). Note also labeling, ventrally, in the lateral mesoderm. Parasagittal section of visceral arches in bright-field $(C)$ and dark-field $(D)$ illumination showing mesenchyme of the visceral arches labeled in discrete regions (arch I, cleft between II and III, putative position of arch IV). Parasagittal section of forelimb bud in bright-field (E) and dark-field $(F)$ illumination showing labeling in the distal and posterior parts of the limb bud and in the lateral mesoderm. Posterior is to the right. All sections treated with probe 1 . Magnifications: $(A, B) 80 \times ;(C-F) 50 \times$. 


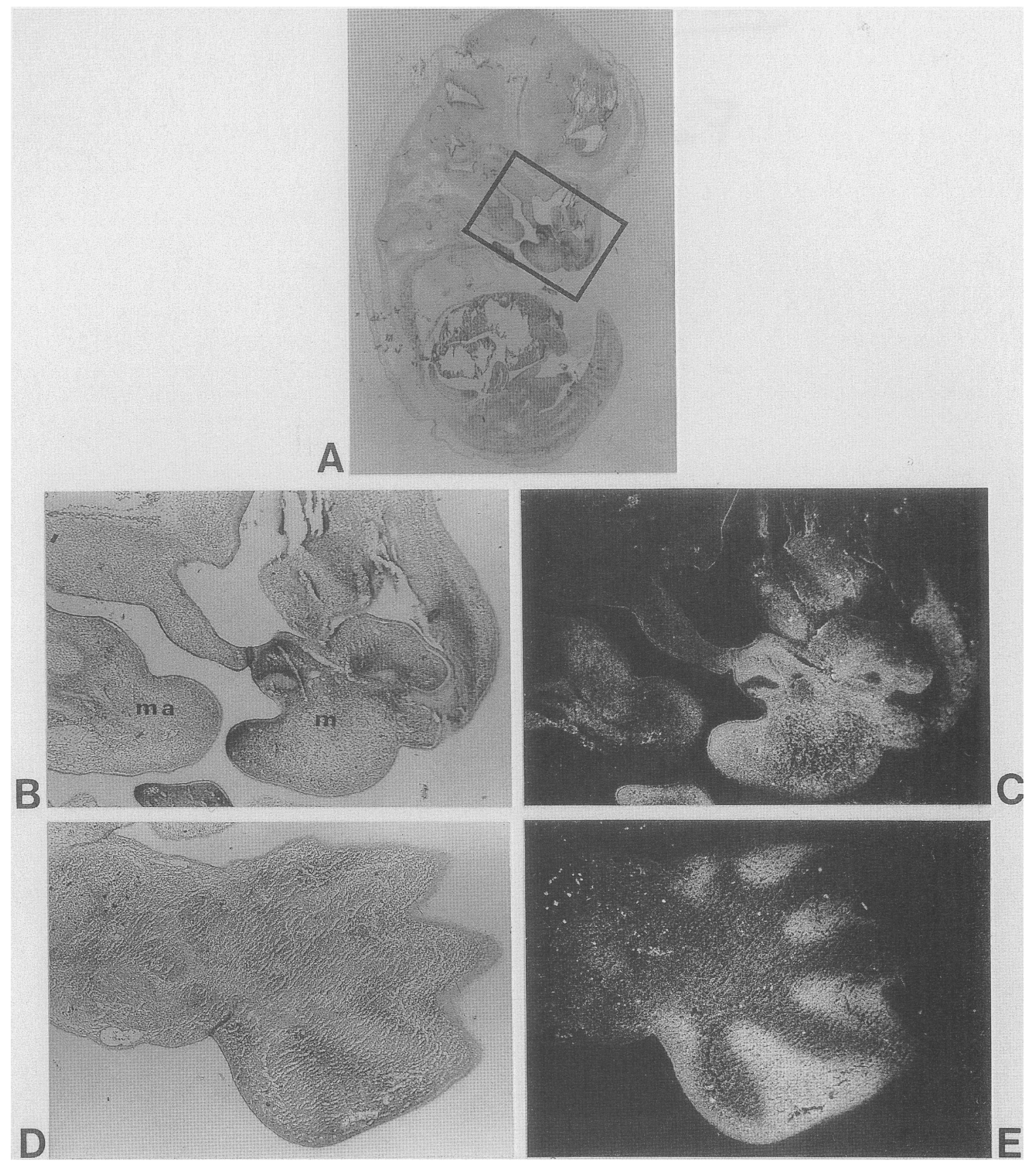

Figure 8. The pattern of expression of $H o x-7.1_{M s h}$ in parasagittal sections of 13.5-day mouse embryos. $(A \mid$ Whole section showing the location of photographs in $B$ and $C$. Midfacial region in bright-field $(B)$ and dark-field $(C)$ illumination, illustrating labeling in the position of the developing maxillary $(\mathrm{m})$ and mandibular $(\mathrm{ma})$ processes. Section though the developing foot plate of the hindlimb in bright-field $(D)$ and dark-field $(E)$ illumination, showing labeling in the interdigital soft mesenchymal tissue. All sections treated with probe 2. Magnifications: $(A) 9 \times ;(B-E) 32 \times$.

the paired family) leads to the prediction that the recognition helix domains of the various genes bind to similar or identical sequences. However, at least in Drosophila, these genes perform highly specific functions during development. Therefore, it is possible that more than just the putative recognition helix is required in DNA binding and that the remainder of the domain may be involved in determining sequence binding specificity. This need not imply that the regions around the helix- turn-helix bind DNA directly but, rather, that the remainder of the homeo box may participate in proteinprotein interactions that would provide the specificity of function needed during embryogenesis. On the basis of the conservation of the homeo box region, we can speculate that these proteins in mouse and Drosophila, at least, share some very similar properties inside the cell.

The Hox-7.1 locus has been assigned to mouse chromosome 5. We have identified at least two other 
members of this family. The genomic organization of these related genes may be similar to that found for the mouse Antp-like genes that are known to reside in several tightly linked multigenic clusters. Alternatively, these genes may be located at different positions, as are the two en-like genes (Joyner and Martin 1987). It is of interest that the mouse mutation luxate $(l x)$ maps within the region of the Hox-7.1 locus. The phenotype of this mutation involves polydactyly and oligodactyly of the hind feet, as well as other bone abnormalities of the hindquarters (Green 1981). The coincidence of the $I x$ phenotype with our observations of $\mathrm{Hox}_{-7.1}$ expression might suggest a direct relationship between this homeo box-containing gene and the mutation. This seems unlikely, because the Hox-7.1 expression pattern is more extensive; however, further analysis of this relationship is warranted.

Hox-7.1 maps $1.0 \mathrm{cM}$ distal to $D 4 S 43$ and $19 \mathrm{cM}$ proximal to Kit on mouse chromosome 5. D4S43 is a polymorphic locus identified in humans that is closely linked to the Huntington's disease gene $(H D)$ on human chromosome 4p (Gilliam et al. 1987; S.V. Cheng et al., in prep.). Kit is a proto-oncogene that maps to human chromosome 4, band q11-q21 (Yarden et al. 1987). These mapping results suggest that $\operatorname{Hox}_{-7.1}$ is part of a large conserved linkage group involving mouse chromosome 5 and human chromosome 4 . In addition to $D 4 S 43$, four other DNA markers located near HD on human chromosome $4 \mathrm{p}$ have mapped to mouse chromosome 5 /S.V. Cheng et al., in prep.). The relative order of these five loci is conserved in mouse and human chromosomes. D4S43 is the most proximal marker of the five loci localized on mouse chromosome 5 . These results strongly suggest that Hox-7.1 is located on human chromosome $4 \mathrm{p}$, just distal to D4S43. In humans, D4S43 maps $1 \mathrm{cM}$ proximal to $H D$. This localization would further suggest that $H D$ and Hox-7.1 lie on opposite sides of D4S43.

The putative DNA-binding function of homeo box gene products, their role in spatial patterning in Drosophila, and the evolutionary conservation of the homeo box motif suggest that these genes play key roles in controlling transcription during the development of complex tissue patterns in the mammalian embryo. In support of this view, homeo box gene expression in the mouse is generally restricted to specific domains in morphogenetically active tissues (for reviews, see Holland and Hogan 1988; Dressler and Gruss 1988). We have noted elsewhere that homeo box genes may play a role in establishing or maintaining the spatial integrity of tissues during complex cellular rearrangements, the vertebrate counterpart of early compartmentalization in the Drosophila embryo (Davidson et al. 1988). The patterns of expression of Hox-7.1 in the limb and neural crest derivatives are consistent with this idea. More importantly, however, they may provide an opportunity to critically examine it. Unlike the sites of expression of other homeo box genes, the limb and neural crest have been used extensively to study fundamental questions of pattern formation by applying classical embryological techniques. Further studies of Hox-7.1 expression in combination with classical experiments may thus provide particular insights into the roles of homeo box genes in mammalian development.

One opportunity for such an analysis is suggested by the pattern of Hox-7.1 expression relatively late in the development of the limb. Hox-7.1 activity is restricted to the interdigital soft tissue in a pattern that matches that of cell death expected in the mouse limb on the basis of comparison with the chick (Saunders and Fallon 1966; Fallon and Saunders 1968). In addition to its involvement in remodeling the foot plate, cell death occurs in the posterior part of the chick wing bud. Our analysis of the mouse forelimb bud suggests that Hox-7.1 is also expressed in this region, though expression extends through the lateral mesoderm. Fallon and Saunders (1968) showed that death in this posterior necrotic zone is preprogrammed and occurs on schedule in tissue maintained in culture. Rescue can be effected by coculture with tissue from different parts of the wing bud. The experimental possibilities of this in vitro assay for cell programming could, perhaps, be exploited to investigate a possible causal relation between $\mathrm{Hox}_{-1.1} \mathrm{ex}$ pression and the maintainance of the program for cell death.

Our results suggest that earlier in limb development, the distal and posterior mesenchyme are sites of peak Hox-7.1 expression. Both of these regions, the former in conjunction with the thickened ridge of apical ectoderm, have been shown to play crucial roles in controlling the patterns of cartilage elements during the development of the chick limb bud at stages similar to those examined here (Wolpert et al. 1975). Indeed, pattern-determining activity has been demonstrated in tissue from the posterior parts of the fore- and hindlimbs of 10-day-old mice grafted to the anterior region of chick wing buds (Tickle et al. 1976). It will be of particular interest to examine the possibility that Hox-7.1 is involved in the specification or maintainence of positional information in the limb by investigating the pattern of expression of the gene at successive stages and the effects of classical limb bud deletions and heterotopic grafts on this pattern.

Our results indicate $\operatorname{Hox}-7.1$ activity in the neural crests in the posterior trunk and tail and in a subset of the midfacial and visceral arch structures that are derived from the cranial neural crests. Heterotopic transplantation experiments in amphibia and birds have shown that region-specific information, acquired by prospective cranial crest cells in the neural plate, later governs the shapes of the facial bones that they form (see Noden 1988). The pattern of Hox-7.1 expression suggests that the gene could play a part in maintaining the regional specificity of spatial pattern information in the crest cells during their migration between the neural plate and the site of morphogenesis.

How might homeo box genes exert their putative influence on pattern formation? One intriguing possibility is suggested by the partial correlation between $\mathrm{Hox}-7.1$ expression and the distribution of the proto-oncogene int-1 in the neural tube (Wilkinson et al. 1987) and the growth factor TGF- $\beta_{1}$ in the limb and in structures de- 
rived from the cranial neural crest (Heine et al. 1987).

Although these results raise interesting possibilities, we have, at present, only circumstantial evidence for a causal relation between Hox-7.1 expression and pattern formation. Morevover, we have assumed that mRNA concentration, as indicated by in situ hybridization, reflects gene function. Immunohistochemical assays for the protein product and functional assays, perhaps based on genetic manipulation of the Hox-7.1 locus, will be required to test these assumptions.

\section{Materials and methods}

\section{Screening of the cDNA library}

Between $10^{5}$ and $10^{6}$ plaques from a $\lambda$ gt 10 library prepared from 8.5-day mouse embryonic mRNA (Fahrner et al. 1987) were used for each screen. The standard Benton and Davis (1977) procedure was used to prepare nitrocellulose replicas from each plate. Hybridizations were performed in $5 \times$ SSC, $10 \%$ dextran sulfate, $4 \times$ Denhardt's solution, $0.2 \%$ SDS, and $0.2 \%$ sodium pyrophosphate. 'High' stringency hybridizations were at $68^{\circ} \mathrm{C}$, and 'low' stringency hybridizations were at $60^{\circ} \mathrm{C}$. Usually, dextran sulfate was omitted at low stringency to reduce background. All probes used for screening were isolated from the plasmid sequence by restriction digestion to release the insert, followed by extraction of the DNA fragment from agarose after gel electrophoresis by passage through Elu-tips (Schleicher and Schuell), according to the manufacturer's description. All probes used for screening were nick translated (Rigby et al. 1977). The Drosophila ftz cDNA was kindly provided by Dr. Walter Gehring.

\section{DNA sequencing}

The inserts from the isolated $\lambda \mathrm{gt} 10$ clones of interest were subcloned into pTZ18U or pTZ19R (Mead et al. 1986). For sequencing, fragments were generated from isolated insert fragments (isolated as above) by restriction digestion or sonication and randomly subcloned into $\mathrm{M} 13, \mathrm{mpl}$, or mpl9 vectors. These single-stranded DNAs were sequenced by the dideoxy chain-termination method (Sanger et al. 1977) using Sequenase (USB, Inc.), according to the manufacturer's directions.

\section{DNA and RNA extractions and blotting analysis}

Extraction of RNA and Northern blot analysis were as described by Meehan et al. (1984). Extraction of DNA was from mouse liver. The extraction procedure and Southern blotting were as described by Hill et al. (1985).

\section{Mapping in interspecific backcrosses}

A total of 204 progeny from an interspecific backcross between (C57BL/6) $\times M$. spretus) $\mathrm{F}_{1}$ females and $\mathrm{C} 57 \mathrm{BL} / 6 \mathrm{~J}$ males were analyzed for each of the seven probes described in Table 1 . The backcross mice were generated at the NCI-Frederick Cancer Research Facility. High-molecular-weight genomic DNAs were prepared from frozen mouse tissue (Jenkins et al. 1982). Restriction endonuclease digestion, agarose gel electrophoresis, Southern blot transfer, and hybridizations were performed as described (Jenkins et al. 1982). The mp2, Il-6, AlbH, and pGus-1 probes were washed as described (B.A. Mock et al., in prep.). The C9AHB1.4, phckit-171, and pMH 22 probes were washed three times in $1 \times$ SSCP and $0.1 \%$ SDS for 30 min per wash.
Statistical analysis of the recombination frequencies from the interspecific backcrosses was performed by calculating the maximum likelihood estimates of linkage parameters, as described by Green (1981), using the computer program 'Spretus Madness' [developed by D. Dave and A.M. Buchberg, NCIFrederick Cancer Research Facility (Frederick, Maryland)].

\section{In situ hybridization analysis}

In situ hybridizations were performed on sections from mouse embryos derived from Swiss matings at 9.5, 10.5, 11.5, and 13.5 days. The cDNA probes were the restriction fragments of the pMH $\lambda 2$ clone indicated in Figure 6, subcloned into the vector pTZ18U in front of the $T_{7}$ RNA promoter (Mead et al. 1986). Synthesis of the ${ }^{35} \mathrm{~S}$-labeled RNA probes and the in situ technique were performed as described previously (Davidson et al. 1988).

\section{Acknowledgments}

We thank Walter Gehring for providing the Drosophila ftz clone, Bernard Jacq for supplying the unpublished protein sequence information of the Drosophila Msh homeo box, and Karen Fahmer and Brigid Hogan for supplying the $\lambda g t 10$ cDNA library. We also thank Shirley V. Cheng and James F. Gusella (Neurogenetics Laboratory, Massachusetts General Hospital, Boston, MA) for a probe representative of the $D 4 S 43$ locus and for providing data prior to publication. We thank Sara Cox for the computer analysis of the primary sequence and establishing potential phosphorylation sites. We thank Sheila Christie and Alison Hall for excellent technical assistance, Norman Davidson, Sandy Bruce, and Douglas Stuart for expert photographic work, and Nick Hastie for valuable discussions and comments on the manuscript. We would also like to thank $M$. Buckingham for bringing to our attention the relationship between Msh and Hox-7.1. This research was supported, in part, by the National Cancer Institute Department of Health and Human Services under contract NOI-CO 74101 with Bionetics Research, Inc.

\section{References}

Akam, M. 1987. The molecular basis for metameric pattern in the Drosophila embryo. Development 101: 1-22.

Awgulewitsch,A., M.F. Utset, C. P. Hart, W. McGinnis, and F. H. Ruddle. 1986. Spatial restriction in expression of a mouse homeo box locus within the central nervous system. Nature 320: $328-335$.

Baron, A., M.S. Featherstone, R.E. Hill, A. Hall, B. Galliot and D. Duboule. 1987. Hox-1.6: A mouse homeo-box-containing gene member of the Hox-1 complex. EMBO I. 6: 2977-2986.

Beachy, P.A., S.L. Helfand, and D.S. Hogness. 1985. Segmental distribution of bithorax complex proteins during Drosophila development. Nature 313: 545-551.

Benton, W.D. and R.W. Davis. 1977. Screening of gt recombinant clones by hybridization to single plaques in situ. Science 196: 180-182.

Boncinelli, E., A. Simeone, A. LaVolpe, A. Faiella, V. Fidanza, D. Acapora, and L. Scotto. 1985. Human cDNA clones containing homeo box sequences. Cold Spring Harbor Symp. Quant. Biol. 50: 301-306.

Breier, G., G.R. Dressler, and P. Gruss. 1988. Primary structure and developmental expression pattern of Hox- 3.1, a member of the murine Hox-3 homeobox gene cluster. EMBO I. 7: 1329-1336.

Bucan, M., T. Yang-Feng, A.M. Colberg-Poley, D.J. Wolgemuth J.L. Guenet, U. Franke, and H. Lehrach. 1986. Genetic and 
cytogenetic localization of the homeo box containing genes on mouse chromosome 6 and human 7. EMBO I. 5: 28992905.

Carrasco, A.E., W. McGinnis, W. Gehring, and E.M. DeRobertis. 1984. Cloning of an $X$. laevis gene expressed during early embryogenesis coding for a peptide region homologous to Drosophila homeotic genes. Cell 47: 409-414.

Carroll, S.B. and M.P. Scott. 1985. Localization of the fushi tarazu protein during Drosophila embryogenesis. Cell 43: 47-57.

Colberg-Poley, A.M., S.D. Voss, K. Chowdhury, C.L. Stewart, E.F. Wagner, and P. Gruss. 1985. Clustered homeoboxes are differentially expressed during murine development. Cell 43: $39-45$.

Davidson, D., E. Graham, C Sime, and R. Hill. 1988. A gene with sequence similarity to Drosophila engrailed is expressed during the development of the neural tube and vertebrae in the mouse. Development 104: 305-316.

Desplan, C.,.J. Theis, and P.H. O'Farrell. 1985. The Drosophila developmental gene, engrailed, encodes a sequence specific DNA binding activity. Nature 318: 630-635.

Di Nardo, S., J.M. Kuner, J. Theis, and P.H. O'Farrell. 1985. Development of embryonic pattern in $D$. melanogaster as revealed by accumulation of the nuclear engrailed protein. Cell 43: 59-69.

Dressler, G.R. and P. Gruss. 1988. Do multigene families regulate vertebrate development? Trends Genet. 4: 214-219.

Evans, R.M. and S.M. Hollenberg. 1988. Zinc fingers: Gilt by association. Cell 52: 1-3.

Fahrner, K., B.L.M. Hogan, and R.A. Flavell. 1987. Transcripts of $H \cdot 2$ and $Q a$ genes in embryonic and adult mice. EMBO $/$. 6: $1265-1271$.

Fallon, J.F. and J.W. Saunders. 1968. In vitro analysis of the control of cell death in a zone of prospective necrosis from the chick wing bud. Dev. Biol. 18: 553-570.

Featherstone, M.S., A. Baron, S.J. Gaunt, M.-G. Mattei, and D. Duboule. 1988. Hox-5.1 defines a homeobox containing gene locus on mouse chromosome 2. Proc. Natl. Acad. Sci. 85: $4760-4764$.

Frigerio, G., M. Burri, D. Bopp, S. Baumgartner, and M. Noll. 1986. Structure of the segmentation gene paired and the Drosophila PRD set as part of a gene network. Cell 47: $735-746$.

Gay, N.J., S.J. Poole, and T.B. Kornberg. 1988. The Drosophila engrailed protein is phosphorylated by a serine-specific protein kinase. Nucleic Acids Res. 16: 6637-6647.

Gehring, W.J. 1987a. Homeo boxes in the study of development. Science 236: 1245-1252.

-1987b. The homeobox: Structural and evolutionary aspects. In Molecular approaches to developmental biology, pp. 115-129. Alan R. Liss, New York.

Gilliam, T.C., M. Bucan, M. Bucan, M.E. MacDonald, M Zimmer, J.L. Haines, S.V. Cheng, T.M. Pohl, R.H. Meyers, W.L. Whaley, B.A. Allitto, A. Faryniarz, J.J. Wasmuth, A.-M. Frischauf, P.M. Conneally, H. Lehrach, and J.F. Gusella. 1987. A DNA segment encoding two genes very tightly linked to Huntington's disease. Science 238: 950-952.

Green, M.C. 1981. Catalog of mutant genes and polymorphic loci. In Genetic variants and strains of the laboratory mouse (ed. M.C. Green), pp. 8-278. Gustav Fischer Verlag, Stuttgart.

Hart, C.P., A. Awgulewitsch, A Fainsod, W. McGinnis, and F.H. Ruddle. 1985. Homeo box gene complex on mouse chromosome 11: Molecular cloning, expression in embryogenesis, and homolgy to a human homeo box locus. Cell 43: 9-18.

Harvey, R.P., C.J. Tabin, and D.A. Melton. 1986. Embryonic expression and nuclear localization of Xenopus (Xhox) gene products. EMBO I. 5: 1237-1244.

Heine, U.I., E.F. Munoz, K.C. Flanders, L.R. Ellingsworth, H.Y.P. Lam, N.L. Thompson, A.B. Roberts, and M.B. Sporn. 1987. Role of transforming growth factor-B in the development of the mouse embryo. J. Cell Biol. 105: 2861-2876.

Hill, R.E., A.E. Hall, C.M. Sime, and N.D. Hastie. 1987. A mouse homeobox-containing gene maps near to a developmental mutation. Cytogenet. Cell. Genet. 44: 171-174.

Hill, R.E., P.H. Shaw, R.K. Barth, and N.D. Hastie. 1985. A genetic locus closely linked to a protease inhibitor gene complex controls the level of multiple RNA transcripts. Mol. Cell. Biol. 5: 2114-2122.

Holland, P.W.H. and B.L.M. Hogan. 1988. Expression of homeo box genes during mouse development: a review. Genes Dev. 2: $773-782$.

Ingham, P.W. 1988. The molecular basis of embryonic pattern formation in Drosophila. Nature 335: 25-34.

Jenkins, N.A., N.G. Copeland, B.A. Taylor, and B.K. Lee. 1982. Organization, distribution and stability of endogenous ecotropic murine leukemia virus DNA sequences in chromosomes of Mus musculus. J. Virol. 43: 26-36.

Joyner, A.L. and G.R. Martin. 1987. En-1 and En-2, two mouse genes with sequence homology to the Drosophila engrailed gene: expression during embryogenesis. Genes Dev. 1: $29-38$.

Joyner, A.L., R.V. Lebo, Y.W. Kan, R. Tjian, D.R. Cox, and G.R. Martin. 1985. Comparative chromosome mapping of a conserved homeobox region in mouse and human. Nature 314: $173-177$.

Kessel, M., F. Schulze, M. Fibi, and P. Gruss. 1987. Primary structure and nuclear localization of a murine homeodomain protein. Proc. Natl. Acad. Sci. 84: 5306-5310.

Klug, A. and D. Rhodes. 1987. Zinc fingers: A novel protein motif for nucleic acid recognition. Trends Biochem. Sci. 12: $464-469$.

Kozak, M. 1987. Analysis of $5^{\prime}$-noncoding sequences from 699 vertebrate messenger RNAs. Nucleic Acid Res. 15: 81258148.

Laughon, A., S.B. Carroll, F.A. Storfer, P.D. Riley, and M.P. Scott. 1985. Common properties of proteins encoded by $A n$ tennapedia complex genes of Drosophila melanogaster. Cold Spring Harbor Symp. Quant. Biol. 50: 253-262.

Levine, M., G.N. Rubin, and R. Tjian. 1984. Human DNA sequences homologous to a protein coding region conserved between homeotic genes of Drosophila. Cell 38: 667-673.

Lonai, P., E. Arman, H. Czosnek, F.H. Ruddle, and C. Blatt. 1987. New murine homeoboxes: Structure, chromosomal assignment, and differential expression in adult erythropoesis. DNA 6: 409-418.

MacDonald, P.M., P. Ingham, and G. Struhl. 1986. Isolation, structure, and expression of even-skipped: A second pairrule gene of Drosophila containing a homeobox. Cell 47: $721-734$.

Martin, G.R., E. Boncinelli, D. Duboule, P. Gruss, I. Jackson, R. Krumlauf, P. Lonai, W. McGinnis, F. Ruddle, and D. Wolgemuth. 1987. Nomenclature for homeo-box-containing genes. Nature 325: 21-22.

Mavilio, F., A. Simeone, A. Giampaolo, A. Faiella, V. Zappavigna, D. Acampora, G. Poiana, G. Russo, C. Peschle, and E. Bouncinelli. 1986. Tissue and stage specific expression of multiple transcripts from a new homeobox gene in human embryonic development. Nature 324: 664-668.

McGinnis, W., R.L. Garber, J. Wirz, A. Kuroiwa, and W.J. Gehring. 1984a. A homologous protein coding sequence in Drosophila homeotic genes and its conservation in other metazoans. Cell 38: 403-408. 
McGinnis, W., M.S. Levine, E. Hafen, A. Kuroiwa, and W.J. Gehring. 1984b. A conserved DNA sequence in homeotic genes of the Drosophila melanogaster Antennapedia and Bithorax complexes. Nature 308: 428-433.

Mead, D.A., E. Szczesna-Skonupa, and B. Kemper 1986. Singlestranded DNA 'blue' $\mathrm{T} 7$ promoter plasmids: A versatile tandem promoter system for cloning and protein engineering. Protein Eng. 1: 67-74.

Meehan, R.R., D.P. Barlow, R.E. Hill, B.L.M. Hogan, and N.D. Hastie. 1984. Pattern of serum protein gene expression in mouse visceral yolk sac and fetal liver. EMBO $/$. 3: 18811885.

Meijlink, F., R. deLaaf, P.Verrijzer, O. Destree, V. Kroezen, J. Hilkens, and J. Deschamps. 1987. A mouse homeobox containing gene on chromosome 11: Sequence and tissue specific expression. Nucleic Acids Res. 15: 6773-6786.

Mlodzik, M., A. Fjose, and W.J. Gehring. 1985. Isolation of caudal, a Drosophila homeo box-containing gene with maternal expression, whose transcripts form a concentration gradient at the preblastoderm stage. EMBO /. 4: 2961-2969.

Muller, M.M., A.E. Carrasco, and E.M. DeRobertis. 1984. A homeo-box-containing gene expressed during oogenesis in Xenopus. Cell 39: 157-162.

Munke, M., D.R. Cox, I.J. Jackson, B.L.M. Hogan, and U. Franke. 1986. The murine Hox-2 cluster of homeobox containing genes distal on chromosome 11 near the tail-short (TS) locus. Cytogenet. Cell. Genet. 42: 236-240.

Noden, D.M. 1988. Interactions and fates of avian craniofacial mesenchyme. Development (suppl.) 103: 121-140.

Palmer, R., P.M. Gallagher, W.L. Boyko, and R.E. Ganschow. 1983. Genetic control of levels of murine kidney glucuronidase mRNA in response to androgen. Proc. Natl. Acad. Sci. 80: $7596-7600$.

Poole, S.J., L.M. Kauver, B. Drees, and T. Kornberg. 1985. The engrailed locus of Drosophila: Structural analysis of an embryonic transcript. Cell 40: 37-43.

Rabin, M., A. Ferguson-Smith, C.P. Hart, and F.H. Ruddle. 1986. Cognate homeo-box loci mapped on homologous human and mouse chromosomes. Proc. Natl. Acad. Sci. 83: $9104-9108$.

Rabin, M., C.P. Hart, A. Ferguson-Smith, W. McGinnis, M. Levine, and F.H. Ruddle. 1985. Two homeo-box loci mapped in evolutionarily related mouse and human chromosomes. $\mathrm{Na}$ ture 314: 175-177.

Rigby, P.W., M. Dieckmann, C. Rhodes, and P. Berg. 1977. Labeling deoxyribonucleic acid to high specific activity in vitro by nick translation with DNA polymerase I. $/$. Mol. Biol. 113: 237-251.

Robert, B., P. Barton, A. Minty, P. Daubas, A. Weydart, F. Bonhomme, J. Catalan, D. Chazottes, J.-L. Guenet, and M. Buckingham. 1985. Investigation of genetic linkage between myosin and actin genes using an interspecific mouse backcross. Nature 314: 181-183.

Sanger, F., S. Nicklen, and A.R. Coulson. 1977. DNA sequencing with chain-terminating inhibitors. Proc. Natl. Acad. Sci. 74: 5463-5467.

Saunders, J.W. and J.F. Fallon. 1966. Cell death in morphogenesis. In Major problems in developmental biology (ed. M. Locke), pp. 289-314. Academic Press, New York.

Scott, M.P. and A.J. Weiner. 1984. Structural relationships among genes that control development: Sequence homology between Antennapedia, Ultrabithorax and fushi tarazu loci of Drosophila. Proc. Natl. Acad. Sci. 81: 4115-4118.

Sharpe, P.T., J.R. Miller, E.P. Evans, M.D. Burtenshaw, and S.J. Gould. 1988. Isolation and expression of a new mouse homeobox gene. Development 102: 397-407.

Shepherd, J.C.W., W. McGinnis, A.E. Carrasco, E.M. DeRo- bertis, and W.J. Gehring. 1984. Fly and frog homeo domains show homologies with yeast mating type regulatory proteins. Nature 310: 70-71.

Simeone, A., F. Mavillo, L. Bottero, A. Giampaolo, G. Russo, A. Faiella, E. Boncinelli, and C. Peschle. 1986. A human homeobox gene specifically expressed in spinal cord during embryonic development. Nature 320: 763-765.

Tickle, C., G. Shellswell, A. Crawley, and L. Wolpert. 1976. Positional signalling by mouse limb polarizing region in the chick wing bud. Nature 259: 396-397.

White, R.A.H. and M. Wilcox. 1984. Protein products of the bithorax complex in Drosophila. Cell 39: 163-171.

Wilkinson, D.G., J.A. Bailes, and A.P. McMahon. 1987b. Expression of the proto-oncogene int-1 is restricted to specific neural cells in the developing mouse embryo. Cell 50: 79-88.

Wolpert, L., J. Lewis, and D. Summerbell. 1975. Morphogenesis of the vertebrate limb. Ciba Symp. 329: 95-130.

Yarden, Y., W.-J. Kuang, T. Yang-Feng, L. Coussens, S. Munemitsu, T.J. Dull, E. Chen, J. Schlessinger, U. Francke, and A. Ullrich. 1987. Human proto-oncogene c-Kit: A new cell surface receptor tyrosine kinase for an unidentified ligand. $E M B O$ \%. 6: 3341-3351. 


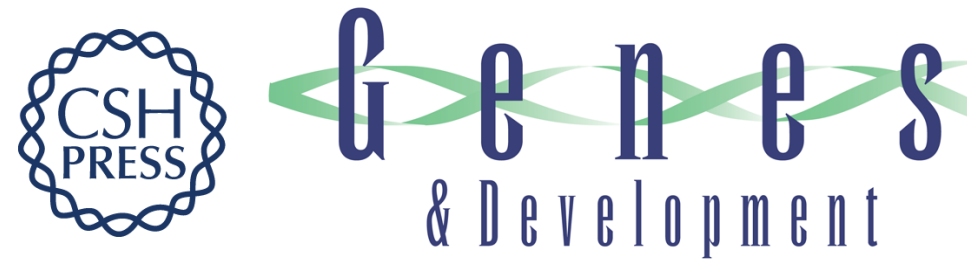

\section{A new family of mouse homeo box-containing genes: molecular structure, chromosomal location, and developmental expression of Hox-7.1.}

R E Hill, P F Jones, A R Rees, et al.

Genes Dev. 1989, 3:

Access the most recent version at doi:10.1101/gad.3.1.26

References This article cites 67 articles, 19 of which can be accessed free at:

http://genesdev.cshlp.org/content/3/1/26.full.html\#ref-list-1

\section{License}

Email Alerting Service

Receive free email alerts when new articles cite this article - sign up in the box at the top right corner of the article or click here.

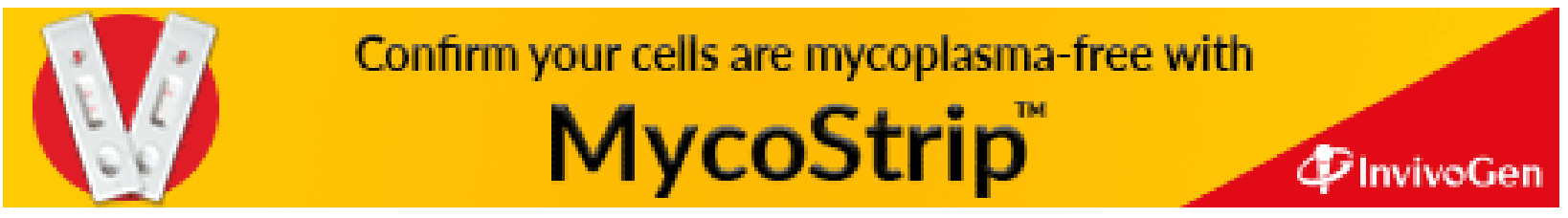

